\title{
Cost Assignments In A Managerial Accounting Contract Logging Context
}

D.J. Kilpatrick, Ph.D., University of Alaska Anchorage, USA

Barbara P. Reider, Ph.D., University of Montana, USA

Cathy Y. Taylor, Alyeska Pipeline, USA

\begin{abstract}
This case describes a firm where the controller is planning to use his expertise in accounting for company-owned timber to consider logging on a contract basis for others. To develop the contract strategy, the controller must understand the firm's costs so that he can prepare competitive bids and provide an adequate profit margin. This case requires students to engage in the first steps of developing a cost management system for a contracting situation. Students must: (1) identify management's information needs, (2) identify cost objects, (3) identify appropriate costs to assign to cost objects, (4) identify potential allocation bases for indirect costs, and (5) describe cost behavior.
\end{abstract}

Keywords: Cost Object; Cost Assignment; Cost Allocation; Cost Driver; Cost Behavior

\section{INTRODUCTION}

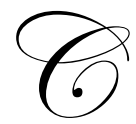

oastal Alaska Logging ${ }^{1}$ (CAL) is a corporation in Southeast Alaska, formed as part of the 1971 settlement of long-standing aboriginal land claims through the Alaska Native Claims Settlement Act (ANCSA). This legislation settled these rights by transferring 44 million acres of land and $\$ 962$ million in cash to 13 regional corporations, organized and chartered under Alaskan law, to manage these assets. In addition, ANCSA created village corporations within each regional corporation to manage local assets. ${ }^{2}$ (Since individual communities were often quite small in population, several of them together usually formed each village corporation.) The stockholders in one Southeast Alaskan village corporation created CAL to operate within the heavily timbered regional corporation of Sealaska, which is adjacent to British Columbia, Canada. Sealaska shareholders are primarily of Haida, Tsimshian, and Tlinget descent.

Formally incorporated in 1973, CAL received rights to over 20,000 acres of land and a cash infusion of approximately $\$ 1$ million. Historically, the main source of revenue for CAL was the logging and export of timber cut from its land in remote locations. Maximizing stockholder value involved the rapid harvest of old-growth timber exported in the form of unprocessed logs. After decades of logging, CAL had harvested the vast majority of its timberland.

The market for spruce, hemlock, and cedar during the peak of CAL's logging activity provided substantial revenue for the corporation and large cash dividends for its shareholders. In anticipation of the eventual harvest of most of the CAL-owned timber, the corporation had diversified its operations into business activities such as gravel mining for the local construction market and the ownership of tourism ventures.

However, CAL's board of directors wishes to continue leveraging its logging expertise. Over the years, CAL has established an experienced logging workforce, a large fleet of owned and leased logging equipment, a convenient system of sort yard use for inventorying harvested logs, and a profitable marketing channel for shipping timber to foreign and domestic customers. In his next business plan, CAL's controller will include a strategy for

\footnotetext{
${ }^{1}$ Name changed

2 The term "Native Corporation" encompasses both regional and village corporations.
} 
transitioning from a strong reliance on the harvest of its own timber for a majority of the corporation's revenue to creating a competitive contract logging operation on nearby non-CAL-owned land. CAL faces several established competing logging businesses in the area.

\section{LOGGING PROCESS}

Profitable logging in remote CAL regions requires a complex system of timber harvest operations and the construction of new roads to access the stands of marketable timber. These roads are narrow, winding, and unpaved. Main haul roads that serve a larger area require considerably more work to construct and may require a layer of gravel for higher volumes of traffic. A large logging machine called a feller buncher is a standard piece of heavy equipment with a tree-grabbing device and a circular saw that cuts trees at their base. Loggers pull cut trees out of the forest using a method called skidding in which they transport logs from the cutting site to a landing. A cable skidder enables a logger to reel out cable and attach it to cut timber. A grapple holds the timber while the skidder drags it to a landing area near a road. Further processing of the timber at the landing sites includes removing limbs, known as delimbing, and cutting the felled trees into logs.

Workers load cut timber onto logging trucks, then transport and pile it in a log sort yard. Laborers called scalers measure the timber to determine the quantity of board feet in a process called log scaling. A log of a certain length and diameter contains a particular number of board feet. Since logs may contain defects that reduce the merchantable wood volume, scalers will often apply deductions to remove the estimated useless volume from the total.

CAL incurs many costs in its logging operations, including those for administrative services, the leasing and financing of equipment, maintenance, fuel, and storage for the equipment when it is not in use. CAL accounts for its labor costs using fully burdened hourly labor rates, including all employer-paid benefits, employment taxes, overtime, and workers' compensation insurance, which varies with the risk of injury for each type of logging position.

\section{UP NEXT FOR CAL}

The CAL controller is developing his next business plan to include a strategy of transitioning from a strong reliance on the harvest of its own timber to establishing a competitive contract logging business. CAL can establish itself as a competitive bidder only if its managers have a solid knowledge of operational and overhead costs. Therefore, the controller is responsible for estimating costs for contract logging operations, ensuring that CAL bids cover all expenses plus an adequate profit margin.

The controller knows that a robust cost management system begins with the identification of cost objects such as products, projects and activities. Once he has identified appropriate cost objects, he must accurately identify, measure, and assign costs to them. In addition, the controller must allocate overhead costs appropriately. He must also identify costs based on their behavior, and determine CAL's cost drivers based on causal factors. The controller has asked you to assist in developing this cost management system.

\section{QUESTIONS}

1. Assume that CAL has already harvested most of its own available timber. Identify the strengths CAL has in place for expanding operations to bid its services to other forest owners in the region.

2. Before expanding its operations and bidding on a particular job, the CAL controller anticipates his managers will have many questions, such as, "What is the overall scope and size of the job?" A properly designed cost management system can provide relevant information to support decision-making when evaluating contracting opportunities. What additional questions can the controller anticipate from CAL's managers? 
3. Define the following terms:

a. cost object

b. direct cost

c. indirect cost

d. cost allocation

e. cost behavior

f. variable cost

g. fixed cost

h. mixed (or semivariable) cost

i. cost driver

4. What does it mean to assign costs to cost objects? Why do managers assign costs to cost objects? Give three examples of possible cost objects for CAL.

5. Refer to your answer to Question 4. For your stated cost objects, identify three direct costs and three indirect costs that CAL managers may consider when bidding on contract logging projects. For each direct cost, identify a basis for assigning it to the cost object. For each indirect cost, identify a potential cost allocation base.

6. Refer to your answer to Question 5. For each cost that you listed, identify a potential cost driver and classify its cost behavior as variable, fixed, mixed (or semivariable), or none of the above.

\section{TEACHING NOTES}

\section{OVERVIEW}

The setting for this case is a firm that plans to use its expertise in logging company-owned land to expand into logging on a contract basis. (While the case is historical, we ask students to assist the controller in making decisions that will impact the firm's future.) The case describes activities involved in logging in remote Alaskan forests. The material presented allows students to take a macro view of management cost systems, while identifying alternative ways to organize costs. Students are engaged in the preliminary steps of developing a cost management system for a contracting operation. They must anticipate management information needs, identify cost objects, assign costs to those cost objects, identify cost allocation bases for indirect costs, and describe cost behavior.

While the case is short and simple enough to cover in one or two class sessions, we have found that it is sufficiently rigorous to challenge introductory management accounting students in applying their knowledge and personal experience to cost issues in a business expansion setting. The instructor may use the case at the beginning of the course during the introduction of basic concepts such as cost objects, direct costs, indirect costs, and cost behaviors. In addition, the case contains content appropriate for use after topics such as job costing, cost allocation, and activity-based costing have been discussed. Students will be able to apply concepts they have learned in the course.

This case may also be adapted for use in upper-division accounting or graduate-level business courses by requiring students to develop a more comprehensive management cost system. For these more advanced students, instructors may use the contract bidding case to cover transfer pricing, depreciation and depletion, and the treatment of costs for pricing decisions versus profitability calculations.

We recommend that instructors either view background videos in class or assign them to students to view before beginning the case. A video that we have found useful is http://www.sealaska.com/object/haa-aanivideos.html to describe the ANCSA and logging in Southeast Alaska. In addition, we recommend short clips from the popular television show Ax Men at www.history.com/content/axmen. Here students can learn logger lingo, favorite tools of the timber trade, and view the construction of logging roads. 


\section{LEARNING OBJECTIVES}

1. Identify important issues to consider when bidding for a job on a contract basis.

2. Define and identify direct costs, indirect costs, and cost objects.

3. Describe causal relationships between cost objects and the particular costs assigned to them.

4. Identify potential cost allocation bases for indirect costs.

5. Describe costs as variable or fixed with respect to appropriate cost drivers.

\section{SOLUTIONS}

1. Assume that CAL has already harvested most of its own available timber. Identify the strengths CAL has in place for expanding operations to bid its services to other forest owners in the region.

CAL has an experienced workforce, logging equipment, customer relations, and an industry infrastructure already in place. Perhaps nearby forest owners are already engaged in logging. If so, CAL may be able to provide its services with a higher level of environmental sensitivity and lower costs.

2. Before expanding its operations and bidding on a particular job, the CAL controller anticipates his managers will have many questions, such as, "What is the overall scope and size of the job?" A properly designed cost management system can provide relevant information to support decision-making when evaluating contracting opportunities. What additional questions can the controller anticipate from CAL's managers?

- $\quad$ Should we bid on the job? Is it in our best interest?

- $\quad$ Are we bidding on too many jobs at once? Can we handle the workload?

- $\quad$ Do we have the expertise necessary for the job?

- Do we have sufficient manpower and resources to do the job?

- What is the overall scope and size of the job?

- What are our expected revenues?

- What are our expected costs?

- $\quad$ How many bidders (i.e., competitors) will there be?

- What are the comparative advantages and disadvantages of the other likely bidders?

- Is it a "low cost" bid situation?

- If we compete on something other than low cost, what value-added services can we provide?

- What are the risks associated with the job?

- If we make a bid, are we legally bound to keep it?

- If we make a bid, are we ethically bound to keep it?

- Are Native Corporations required to pay taxes on a particular job? Is there an exemption?

- Is there a minimum labor rate for a particular job, such as with certain federal contracts?

- Is there an incentive for hiring minority employees?

3. Define the following terms:

a. cost object

b. direct cost

c. indirect cost

d. cost allocation

e. cost behavior

f. variable cost

g. fixed cost

h. mixed (or semivariable) cost

i. cost driver 
Students may refer to their textbooks for these definitions. The following information is adapted from Garrison, Noreen and Brewer, Managerial Accounting, 14e, McGraw-Hill, 2012.

a. A cost object is anything for which managers need cost data. Examples include products, customers, jobs, activities, and divisions in an organization.

b. A direct cost is a cost that managers can easily and conveniently trace to a specified cost object. In order to trace a direct cost to a cost object, the cost object must cause the direct cost.

c. An indirect cost is a cost that managers cannot easily and conveniently trace to a specified cost object. Indirect costs benefit multiple cost objects, such as the salary of the company's president.

d. Since indirect costs cannot be easily charged to specific cost objects, they must be allocated. This simply means that these costs are assigned to cost objects by using some type of averaging methodology. There is nothing completely fair about cost allocation; it is practically inevitable that managers will charge some cost objects too much, while others will be charged too little.

e. Cost behavior refers to how total costs respond to changes in activity levels. Descriptions of cost behavior include variable, fixed, mixed (or semivariable), and step.

f. A variable cost changes, in total, in direct proportion to changes in activity levels. The cost per unit remains constant within a reasonable, relevant range of activity; only the total changes.

g. A fixed cost is a cost that remains constant, in total, regardless of changes in activity levels within a reasonable, relevant range of activity.

h. $\quad$ A mixed (or semivariable) cost has both variable and fixed components.

i. A cost driver causes a cost to be incurred. If a company did not have the cost driver, it would not bear that particular cost.

4. What does it mean to assign costs to cost objects? Why do managers assign costs to cost objects? Give three examples of possible cost objects for CAL.

Cost assignment identifies specific amounts of direct and indirect costs as associated with particular cost objects. When assigning costs, a manager classifies a cost as direct or indirect with respect to a particular cost object, such as a project. The manager will ask, is it economically feasible to trace a particular cost to a particular project? Is the cost shared by multiple projects? If the manager can easily trace it to a particular project, it is a direct cost. If multiple projects share the cost, it is an indirect cost and the manager may assign it to different projects using an appropriate allocation base.

Managers assign costs for pricing decisions, evaluating the profitability of business segments, and providing incentives in monitoring resource consumption.

Cost objects may include activities such as bidding, road construction, transporting equipment and laborers to a logging site, cutting, skidding, delimbing, bucking, loading and transporting to a sort yard, staging, scaling, and shipping to customers. Cost objects may include sites such as administrative offices, timber stands, landing sites, the loading point, the sort yard, and the customer delivery point. Other cost objects include items that would have many costs assigned to them, such as specific jobs or customers. On the other hand, cost objects that are much narrower in scope include an individual job position in a company or an individual piece of equipment.

5. Refer to your answer to Question 4. For your stated cost objects, identify three direct costs and three indirect costs that CAL managers may consider when bidding on contract logging projects. For each direct cost, identify a basis for assigning it to the cost object. For each indirect cost, identify a potential cost allocation base.

Students prepared responses such as these using "road construction" as their cost object. 


\begin{tabular}{|c|c|c|}
\hline Cost & $\begin{array}{l}\text { Direct or } \\
\text { Indirect }\end{array}$ & $\begin{array}{c}\text { Cost Assignment or } \\
\text { Allocation Base }\end{array}$ \\
\hline Gravel (foundation layer underneath concrete/asphalt layer) & Direct & Pound \\
\hline Concrete/asphalt (primary surface layer) & Direct & Pound \\
\hline \multicolumn{3}{|l|}{ Trucks and equipment } \\
\hline Cement mixers (hauling and mixing cement for surface layer) & Indirect & Hours or mileage \\
\hline Steamrollers (flattening/evening concrete layer) & Indirect & Hours or mileage \\
\hline Shovels (used by workers for any necessary digging) & Indirect & Labor hours \\
\hline Survey equipment (used in the planning process for determining road locations & Indirect & Hours or mileage \\
\hline Loaders (removal of debris and obstacles) & Indirect & Hours or mileage \\
\hline Dump trucks (removal of debris from construction areas) & Indirect & Hours or mileage \\
\hline Paint (lane dividers and lane borders) & Direct & Gallon \\
\hline \multicolumn{3}{|l|}{ Crash barriers } \\
\hline Metal (impact barrier) & Direct & Sheet of steel \\
\hline Wood (support for impact barrier) & Direct & Pound \\
\hline \multicolumn{3}{|l|}{ Sewer access, if needed } \\
\hline Metal (manhole covers and ladder rungs) & Direct & Unit \\
\hline Concrete (housing collar for manholes) & Direct & Pound \\
\hline \multicolumn{3}{|l|}{ Labor } \\
\hline Administrative (managers and site foremen) & Direct & Hour \\
\hline Workers & Direct & Hour \\
\hline
\end{tabular}

6. Refer to your answer to Question 5. For each cost that you listed, identify a potential cost driver and classify its cost behavior as variable, fixed, mixed (or semivariable), or none of the above.

Responses will be contingent on answers to Question 5. Students should have identified cost drivers as potential allocation bases in Question 5. They should appropriately describe how costs respond to changes in levels of the cost driver.

\section{TEACHING PLAN}

Students in the authors' introductory accounting classes have often expressed the desire to start their own businesses or eventually to rise to the position of a company executive officer. One motivation for developing this case was to allow students to consider what skills they would need as an entrepreneur or executive by requiring them to identify important issues in a business expansion setting. Without a single calculation, students are engaged in the preliminary stages of developing a management cost system for a real, though historical, company. When completing the case, students will learn that they can view a particular firm's cost management system in a variety of ways, such as by activity or location, and that they have flexibility in organizing the cost system. The instructor may assign students to work individually or in small groups on this case. Students must demonstrate their ability to write effectively; this case allows an instructor to assess written communication skills.

\section{Introduction of the case}

An instructor can begin the case discussion by asking students to identify the information necessary to successfully bid for a project, regardless of industry. The instructor may highlight the importance of having a sound understanding of the firm's costs, its profit planning goals, and the management strategy for making pricing decisions. Important topics include understanding the competitive environment, the risk of losing a bid if overpricing occurs, the risk of losses if underpricing or cost overruns occur after winning a bid, the legal obligations of bidding, and the ethical dilemmas associated with accepting a job without fully understanding its implications. 


\section{Review of cost objects, direct costs, indirect costs, and cost behaviors}

The material for managerial accounting courses often covers cost objects, direct and indirect costs, and cost behavior in the context of production or merchandising. Before focusing on the logging industry, we prepared students for the case by using retail stores, a familiar setting, to review these concepts.

For a national retail chain, organizational units such as regions, stores, departments, and product lines were identified as cost objects:

Headquarters:

States within a region:

Cities within a state:

Stores within a city:

In-store functions:

Sales Department:

Product Lines:
Northeast, South, Midwest, West

Identify specific states

Identify specific cities within a state

Identify specific store locations within a city

Identify areas such as administration and sales

Identify categories such as sporting goods and clothing

Identify particular brands of men's clothing

Next, we discussed whether a particular cost was direct or indirect with respect to a particular cost object. We used examples such as a men's clothing department as the cost object. Direct costs include the cost of goods sold and the sales employee's commission on the transaction. Indirect costs include cashier wages, the store manager's salary, store security, utilities, depreciation on store fixtures, the customer service department, store insurance, and property taxes. We point out that the classification of costs as direct or indirect depends on the cost object.

We also point out that cost objects do not need not be physical locations. Examples of activities that managers can use as cost objects for the retail chain include the following: purchasing, receiving, sorting, stocking, sales, collections, and customer service.

Finally, we focus on cost behaviors as variable, fixed, or some combination of the two. This step requires students to identify appropriate activities or cost drivers. For a particular department of a retail store, management may use the level of sales as the activity to determine whether costs are variable or fixed. Examples of variable costs include the cost of merchandise sold and sales commissions. Fixed costs include the store manager's salary. The cost of utilities may be a combination of variable and fixed, depending on the pricing schedule for the area. For example, electricity bills and water usage will probably increase with more customer activity.

\section{Suggestions for using the case in upper-division or graduate classes}

Instructors may use this case in upper-division accounting classes or graduate business classes. Students may be required to develop a more comprehensive costing system for CAL's contract logging business, and to consider additional questions such as the following:

- Depreciation expense is required for calculating profit, but it is not a cash flow. How should CAL treat the depreciation of fixed assets if it expands into contract logging? Are they relevant costs in calculating bids for contracts?

- $\quad$ CAL must cover all costs, including indirect costs such as corporate overhead, in order to be profitable. What consideration should CAL give to indirect costs in the bidding process? Should each division in the regional corporation be allocated a portion of the indirect costs to cover? What measures, such as return on investment or residual income, might provide incentives to division managers to earn an adequate return?

- What role might transfer pricing play if the rock and gravel mining division of CAL sells gravel to the contract logging division for building roads to harvesting sites? Would low transfer prices enable the contract logging division to be more competitive? What factors might the rock and gravel division consider in setting "fair" transfer prices?

- In bidding for a contract, CAL managers should consider not only their costs, but also their customers and competitors. What additional information is helpful to have regarding CAL's potential customers and competitors? 
- $\quad$ ANCSA requires that " $70 \%$ of all revenues received by each Regional Corporation from the timber resources and subsurface estate patented to it pursuant to this Act shall be divided annually by the Regional Corporation among all twelve Regional Corporations" 43 U.S.C. $\S 1606(i)$. The purpose of this requirement is to "level the playing field" among regional corporations that are rich or poor regarding their allotted natural resources. How do you think this sharing requirement affects management decisions when faced with opportunities to develop natural resources?

\section{CONCLUSION}

The authors tested the case by using it as either an in-class and out-of-class extra credit assignment in four sections of an introductory managerial accounting class. Almost all of the students in the sections chose to engage in the assignment, and the instructors were impressed with student interest in the case and their thoughtful responses to the questions.

The students did well in identifying cost objects and costs associated with them, and in some instances they thought of costs that had not been considered by the authors. In one class, a student noted the importance of good safety practices, not only because they reduce the direct costs associated with injuries, but also because of the indirect effect of injuries on workers' compensation coverage costs.

The case also requires students to classify costs as direct or indirect, as well as identify potential allocation bases for the indirect costs. In general, students generally did well on this question, but the answers were not as complete as they could have been. Students were able to identify cost objects, but the students who did the case as an in-class exercise usually listed only three or four examples each of direct and indirect costs associated with a cost object. On the other hand, students who worked on the case outside of the class listed more direct and indirect costs for each cost object. In some cases, it appeared that students made some underlying assumptions when classifying costs as direct or indirect that they did not communicate. For example, most students classified the maintenance cost of equipment as indirect but some students considered it a direct cost. Both classifications could be justified, based on underlying assumptions, so students did not always communicate their thoughts in a complete manner. Overall, however, students did well in their responses.

In summary, the students demonstrated success in achieving the learning objectives for this case. Students and instructors alike expressed their enjoyment at this approach to the topic. It is short and simple enough to cover in just a few class sessions, yet there is enough material to challenge students in thinking about cost issues without getting involved in complicated calculations. Students applied their understanding of cost management concepts and their practical work experience in a new context.

\section{EPILOGUE}

When CAL developed and implemented its contract logging business strategy, state and private timber harvests had been providing about two-thirds of the employment in Southeast Alaska for many years. Although harvests had declined in comparison to the past two decades, private activity was consistent and the outlook for sustained timber harvest levels was positive. Sealaska, the largest private landowner in the region, provided a significant part of the regional harvests and exported a majority of its timber through facilities in the CAL region. Federal land management decisions diminished uncertainty over available timber supplies on public lands and increased opportunities to bid on logging activity generated by timber sales. Note that these logging activities occur while maintaining good stewardship of natural resources. For years, private and government-run timberland owners have run silviculture programs (the study of forest management) to help ensure the health of forests. Strategies include pre-commercial tree thinning as well as tree planting on harvested lands that will provide continued habitat for wildlife and high quality timber for future harvests.

Five years after CAL launched its business focus on contract logging, the board of directors decided to discontinue its logging operations. Competition for the logging of available timber harvests was steep; several other regional logging contractors also decided to discontinue operations. However, road building and construction activities in the CAL region had greatly increased with funding from the federal government for infrastructure 
development. CAL was successful in obtaining contracts from both the U.S. Forest Service and other development projects. The company was able to leverage the work done on determining costs for road building to remain competitive for these new opportunities as long as possible.

\section{ACKNOWLEDGMENTS}

We thank participants of the Western Decision Sciences Institute Annual Meeting, the Institute of Management Accountants Annual Conference and Exposition, and the American Accounting Association Annual Meeting for feedback on earlier drafts.

\section{AUTHOR INFORMATION}

D.J. Kilpatrick is an associate professor of accounting at the University of Alaska Anchorage. Her teaching areas include managerial accounting and financial accounting. E-mail: djkilp@uaa.alaska.edu

Barbara Reider is an accounting professor at the University of Montana and a holder of the John and Kathy Connors Faculty Fellowship. Her teaching areas include managerial accounting and government accounting. E-mail: barbara.reider@business.umt.edu

Cathy Taylor is accounting director at Alyeska Pipeline and past president of the Alaskan Chapter of the Institute of Management Accountants. E-mail: taylorc@alyeska-pipeline.com

\section{REFERENCE}

1. Garrison, R.H., E. W. Noreen, and P. C. Brewer, Managerial Accounting, Fourteenth edition, York, NY: McGraw-Hill/Irwin, 2012. 
Journal of Business Case Studies - November/December 2011 Volume 7, Number 6 NOTES 